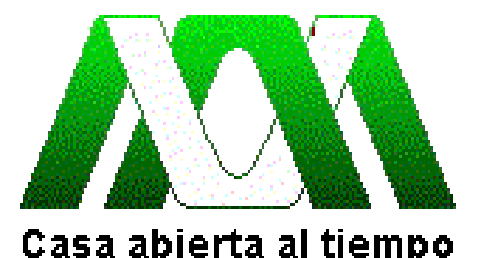

UNIVERSIDAD AUTÓNOMA METROPOLITANA

UNIDAD IZTAPALAPA

DIVISIÓN DE CIENCIAS SOCIALES Y HUMANIDADES

POSGRADO EN CIENCIAS ANTROPOLÓGICAS

Movilidad en la metrópoli ¿Cómo la habitamos?

Sandra Tanisha Silva Aguilar

\author{
ENSAYO \\ Para obtener el Diploma de Especialización \\ en Antropología de la Cultura \\ Director: Dr. Néstor García Canclini
}

México, D.F.

Julio de 2017 


\section{Movilidad en la metrópoli ¿Cómo la habitamos?}

"A diario juramos abandonarla y a diario nos entregamos a su abrazo; es la irrenunciable compañía que merecemos. Que otros vivan en las ciudadelas del orden y el tránsito feliz. Nosotros exigimos el carácter complicado y la belleza ambigua de la mujer barbuda."

Juan Villoro

\section{La relación de cultura, el concepto de habitar y la metrópoli}

Si bien existen distintos abordajes teóricos para estudiar la configuración y el desarrollo de las ciudades en América Latina permanecen rasgos que son imposibles de eludir: el primero, la relación histórica que tiene la ciudad con el espacio público; el segundo, a principios de los años ochenta, la transformación de la ciudades latinoamericanas debido a la entrada del Neoliberalismo y el impacto que tuvo éste para pensar el espacio público.

Uno de los rasgos característicos de la era Neoliberal es la reducción del Estado como proveedor de servicios para la sociedad, así como el detrimento que tuvo éste frente a la regulación que tenía sobre el espacio. A partir de ese momento, el Estado fue remplazado por administraciones privadas que regularon lo público mediante un atributo poco común, la reglamentación del uso público con tintes privatizadores.

El embate neoliberal hizo que la ciudad se rigiera más por el peso del mercado que por efecto de las políticas públicas, lo cual condujo a que el espacio público, por un lado, perdiera su funcionalidad original de ordenador de la ciudad y, por otro, operara como un freno para la acumulación del sector privado. [...] Por ello, el 
espacio público termina siendo el ámbito más significativo del conflicto urbano, sea como asedio por parte del capital o como expresión e integración de la sociedad. (Carrión, 2016, p. 15)

Lo anterior conllevó a lo que se le denomina urbanismo insular (Giglia, 2013), es decir, espacios casi aislados, con pocas conexiones con el resto de la urbe, una especie de distinción frente a los otros espacios de la misma ciudad. Esto ha generado nuevas practicas urbanas e incluso cambios a nivel espacial, pero también a nivel económico, donde las actividades financieras, el consumo, entre otros, cambiaron de lógica; caso paradigmático de lo insular lo encontramos en la Ciudad de México, en específico el megaproyecto Santa Fe, más adelante se abordará el tema.

La presencia creciente de los espacios insulares, en la forma tanto de lugares privados para el uso público (centros comerciales, edificios de oficinas, parques, etcétera) como de lugares que privatizan una porción del espacio de proximidad colocándolo en el adentro (conjuntos residenciales cerrados o calles privatizadas), obliga a repensar la definición canónica de espacio público [...] (Ibídem, p.31).

El espacio público debemos analizarlo no únicamente como un territorio físico espacial sino también como producto de encuentros, desencuentros y relaciones sociales. Si partimos desde lo antes señalado se puede reconstruir la interacción social de diferentes lugares de la ciudad sin olvidarnos de la movilidad que también forma parte del espacio público; si asociamos estos dos conceptos, entendemos entonces que: "[...] el espacio público por excelencia es la centralidad urbana, lugar desde donde se parte, a donde se llega y desde donde se estructura la ciudad". (Carrión, 2016, p. 25)

El espacio público se vuelve la pieza de engranaje para pensar ciudades, a través de éste se construyen y reconstruyen las urbes. Además, el espacio nos permite acercarnos a la idea de cultura puesto que nos vincula con lo otros y al mismo tiempo con nuestro entorno; éste último no sólo atañe a las personas con las que interactuamos sino también con el espacio social y físico en el que transitamos y habitamos. 
Habitar, como diría Angela Giglia (2012), nos permite ubicar al sujeto en un orden socio-espacial temporal que dará lugar a reconocer y establecer dicho espacio. Es entonces que la metrópoli tiene distintas formas de ser habitada y es de suma importancia analizar los procesos urbanos desde la vivencia de los sujetos.

Por ende, habitar cobra relevancia "[...] en la medida en que la cultura nos permite vincularnos a la realidad, a nuestro alrededor, y existir como sujetos conscientes de nosotros mismo, con memorias y proyectos, estudiar el habitar no es más que otra forma de pensar lo cultural en cuanto facultad humana elemental". (lbídem, p. 5)

Aunado a lo anterior, habitar las ciudades depende de la construcción y regulación de ese espacio en contextos históricos específicos. La diferencia, en la actual ciudad neoliberal, radica en que no sólo se entiende a partir de la dicotomía espacio público y privado, o en su caso residencia y trabajo; sino que a su vez, se vive y se habita a la ciudad mediante sus distintas formas de movilidad para arribar a dichas bifurcaciones espaciales.

Los traslados urbanos están imaginados y habitados desde los espacios insulares, la mancha urbana, el ritmo acelerado de las ciudades, la mala planeación de las vías de circulación que nos obligan a ceder el tiempo varias horas del día ${ }^{1}$; el lugar de partida casi siempre la casa, el lugar de llegada puede ser el trabajo, la escuela, la plaza comercial, el mercado, etc. (pero son dos viajes, la ida y la vuelta). Estudios afirman que los transeúntes que habitamos la Ciudad de México atravesamos alrededor de 100 kilómetros de sur a norte y de regreso (Canclini, Castellanos, Rosas, 2013).

Ahora bien, es necesario desdibujar que este desplazamiento sumado al espacio público y a las interacciones que se dan en estos también atañe a una

\footnotetext{
${ }^{1}$ Tomtom Traffic Index señaló que en 2016 México ocupaba el primer lugar con tráfico en el mundo, con un $59 \%$ extra del tiempo en los traslados. (Aguirre, 2017, p.10).
} 
problemática que tampoco es posible esquivar y que impacta a las clases populares, pero también a las más privilegiadas.

[...] unos y otros sufren la prolongación abrumadora de los viajes, la ineficiencia de los transportes públicos, los daños irreversibles a la ecología y especialmente la 'igualitaria' contaminación del aire en toda la ciudad. Aunque los grupos con mayores recursos se protegen con el aire acondicionado de los coches y los purificadores de casa y oficinas, las oportunidades de que la ciudad se vuelva una experiencia agobiadora y delirante están mucho más 'democráticamente repartidas' que otros bienes urbanos". (Ibídem, p. 43)

No obstante que la problemática de movilidad permea a todas las clases sociales, la forma en la que impacta y cómo la resolvemos se vuelve aún más complicada dependiendo de la clase social a la que pertenecemos y los recursos económicos con los que contamos para sortearla. Lo anterior, necesariamente se expresa en desigualdad urbana y de movilidad.

\section{Abordaje de Movilidad en la Ciudad de México.}

Abordar la movilidad metropolitana, significa pensar que la ciudad no es estática y es a partir de su construcción histórica que se ha ido modificando según los periodos. Fue a inicios del siglo XX con el Porfiriato -y el intento de comunicar y transportar la producción del norte del país con la del sur y viceversa- que se construyeron vías férreas en todo el territorio. Tiempo después vinieron los tranvías que trasladaron a las personas en el centro de la Ciudad de México; ya pasada la Revolución, para 1917, se pusieron al servicio de los usuarios de transporte el camión de pasajeros (Ibídem).

Varias décadas posteriores, en los años cuarenta del siglo $\mathrm{XX}$ con el impacto de la industrialización y la explosión demográfica como consecuencia de las múltiples migraciones campo-ciudad, se reconfiguró la Ciudad de México. Para la década de los cincuenta, en el mandato de Miguel Alemán se estrenaron los primeros circuitos viales de la ciudad de México, como el Viaducto Rio Piedad, si 
bien éste se construyó por partes, fue hasta el gobierno de Adolfo López Mateos que se concluyó dicha obra.

Años posteriores en 1967, esta transformación de la ciudad culminó con la aparición del metro como respuesta a una ciudad bastante congestionada, pero también con la encomienda de que el mundo volteara a ver a esta urbe como moderna y progresista. No es casualidad que el metro se inaugurara un año antes de las Olimpiadas de 1968 en la que muchos turistas viajarían y se trasladarían a las distintas sedes, a los hoteles y los lugares turísticos por excelencia (Álvarez, 2010)

En los años siguientes, la respuesta de las autoridades a la mancha urbana que se plasmó diariamente en congestionamientos debido al desplazamiento de la población de sus hogares a los trabajos y viceversa, fue de poco alcance e incluso contradictoria. Para los años noventa y principios de los dos mil, se incentivó el uso del automóvil, la eliminación de la tenencia, la construcción de nuevos circuitos viales -como el segundo piso-; al mismo tiempo, se impulsó el uso de la bicicleta y otras forma de movilidad como el transporte público (Capron y Pérez, 2016)

Fue entonces que la movilidad también se reconfiguró en dos paradigmas: por un lado, tiempo-costo, en el que se piensa que a mayor velocidad, menor tiempo y mayor beneficio económico; es decir, sólo se analiza el tiempo realizado del punto de partida al punto de llegada. Por otro lado, el nuevo paradigma en el que sobresalta la experiencia del trayecto, no se analiza exclusivamente el movimiento del transporte, sino también el movimiento del individuo en el espacio, en otras palabras, "El que se mueve ahora es el individuo y no la unidad de transporte, por lo que los traslados dejan de ser percibidos como una demanda derivada, para convertirse en una actividad realizada por las personas". (Ibídem. p. 13)

No obstante, en lugar de separar ambos paradigmas, combinarlos nos permite entrelazar la situación estructural de la problemática de movilidad, sin 
dejar a un lado la agencia y vivencia de los sujetos. Lindón (2006) menciona que el espacio cumple una elemento indisoluble con el sujeto, pensar que el espacio es móvil nos permite señalar que también habitamos desde el movimiento y no sólo desde los lugares estáticos.

[...] nuestros escenarios son "móviles", unos más y otros menos. Esto quiere decir que no se trata de una representación del narrador que está fijada en un espacio, como en general ocurre con los escenarios goffmanianos. Son escenarios móviles porque el personaje principal está en movimiento, está desplegando diferentes prácticas en varios "aqui", hay deslizamiento de la espacialidad a partir de las prácticas". (p.19)

El sentido que las personas le atribuyen al viaje depende no sólo de la clase social y del transporte utilizado sino de lo que va impactando en el propio viaje y en la experiencia vivida por los sujetos. Pueden existir individuos con agorafobia ${ }^{2}$ debido a los asaltos o a la violencia ejercida hacia ellos en el propio trayecto o transporte público; pero del mismo modo, también puede hallarse este mismo miedo en los automovilistas. Es decir, las múltiples movilidades cambian dependiendo de la experiencia de los sujetos y no sólo del modo de transporte que se utilice, que muchas veces puede ser el mismo.

A veces, ese sentido de inseguridad, incluso de pánico, llega a producir la autoexclusión del sujeto de cierto lugares, sin embargo en muchas circunstancias, el sujeto no puede excluirse de ese lugar porque ese lugar está necesariamente incluido dentro de sus prácticas espaciales cotidianas, y por eso lo fragiliza aún más que si fuera una exclusión radical. (Ibídem, p.16)

\footnotetext{
${ }^{2}$ Agorofobia se entiende como el miedo o el sentido de peligro que se puede tener en un cierto territorio (Lindón, 2006, p. 16)
} 


\section{El impacto de la desigualdad urbana en la movilidad de la Ciudad de México.}

"A pesar de los colapsos urbanos y las innumerables tragedias cotidianas que provoca, el coche es hoy el rey de nuestra vida diaria, y ha hecho del cuerpo algo superfluo para millones de nuestros contemporáneos. La condición humana ha devenido condición sentada o inmóvil, ayudada por un sin número de prótesis".

David Le Breton

La Ciudad de México es una de las principales metrópolis (Duhau y Giglia, 2008) de América Latina. Se trata de una ciudad que tiene una densidad poblacional elevada, un aumento de la concentración espacial y una falta de planeación territorial que demuestran la enorme desigualdad social que se vive. El Reporte Nacional de Movilidad Urbana en México menciona que: "Resalta por su magnitud y complejidad la Zona Metropolitana del Valle de México (ZMVM), donde cerca de 21 millones de personas conforman la mayor concentración urbana, económica y financiera de México y América Latina". (ONU-Hábitat, 2015, p. 18)

Esta desigualdad es el cúmulo de distintos procesos que pasan por lo económico, social, cultural y simbólico. Una de las principales características de esta metrópoli es la desigualdad que se observa en el espacio urbano tanto público como privado y en la forma de desplazarnos al interior de la ciudad (lbídem, p.13).

Uno de los principales factores que inciden en la problemática de movilidad y que a su vez se traduce en desigualdad es la preferencia del transporte motorizado sobre cualquier otra forma de desplazamiento, a saber:

En la ZMVM el $29 \%$ del total de viajes diarios (alrededor de 6.3 millones) se realizan en automóvil privado y el $60.6 \%$ en transporte público concesionado de baja capacidad (microbús, combis, autobús suburbano y taxi); sólo un $8 \%$ se realiza en sistemas integrados de transporte público masivo (Metro, Metrobús, 
Tren ligero y Trolebús) y un $2.4 \%$ en bicicleta y motocicleta (INEGI, 2007). La velocidad promedio se encuentra en franca caída y actualmente, en horas pico, se ubica entre 8 y 11 km/hora (lbídem p. 42 ).

Esto quiere decir que si sumamos el número de personas que viajan en automóvil privado, más los que se desplazan en transporte público concesionado de baja capacidad, nos da casi el $90 \%$ de la forma en la que los habitantes de la Ciudad de México se trasladan. No son entonces sorprendentes los embotellamientos viales y congestiones diarias que permean los distintos espacios de esta metrópoli y zonas conurbadas. ${ }^{3}$

La desigualdad toma aquí dos lógicas: por una parte, los habitantes de la Ciudad de México han naturalizado, en el imaginario común, el confort de un automóvil privado o transporte público concesionado (taxi, uber, etc.) sobre los tiempos de traslado. Por otra parte, la familiaridad y resignación a las grandes distancias en la que las personas se desplazan de su casa al trabajo y viceversa, y que incide aún más en la problemática de urbanidad insular. Los insuficientes transportes públicos como el metro o metrobús que en horas pico se vuelven muy complicados para acceder, entre otros problemas que entorpecen y normalizan la forma de movilidad en México.

En realidad, las personas tienen poco margen de maniobra para no sufrir los inconvenientes ligados a los distintos modos de transporte y sólo realizan pequeños ajustes para hacer el viaje más agradable. Por esta razón, una de las actitudes más generalizadas entre los usuarios de transporte público y los conductores es la resignación. Interiorizan las desventajas ligadas a sus respectivos modos de traslado y normalizan la situación. Los constantes embotellamientos llevan a integrar los tiempos largos de traslado como parte de una rutina y a juzgarlos algo normal y necesario. (Capron et al, 2016, p.15).

\footnotetext{
${ }^{3}$ Datos del cuarto informe de gobierno de Miguel Ángel Mancera señalan que al 30 de junio de 2016 el Padrón Vehicular Particular contaba con 5 millones 213 mil 816 vehículos. Además, en cuanto a los traslados en taxis, diariamente se realizan 1 millón de traslados. Para mayor información puede consultar: http://www.cdmx.gob.mx/storage/app/uploads/public/57d/c84/8ce/57dc848ceb3d09203332 96.pdf
} 
Así, la forma de movilidad -que es parte de un lugar dentro del espacio público habitable- se vuelve un Bien Común (Giglia, 2013) que está en disputa entre los sectores más excluidos y los que cuentan con mayor capital social y económico para trasladarse; la gestión por dicho espacio se vuelve un campo de lucha en el que asemeja a un cable de tensión que se encuentra próximo a reventar.

En otras palabras, la deficiente movilidad provoca distintas formas de disputa entre las personas que constantemente son excluidas y las que tienen preeminencia sobre ellas y sobre los transportes más cómodos, es decir:

Se tiende a aceptar [...] que la movilidad representa en sí misma un objeto de disputa, atravesado por conflictos sociales y políticos, desde donde se configuran prácticas de resistencia al modelo hegemónico automóvil intensivo (y sus manifestaciones ideológicas), así como a las relaciones de poder cristalizadas en el sistema de transporte (Apaolaza, 2012, p.8).

La falta de un espacio público incluyente se vuelve una de las principales violaciones sobre los derechos que tienen los habitantes sobre la ciudad, "el derecho al espacio público como derecho a la inclusión porque [...] el 'respeto al derecho ajeno es la paz': la alteridad." (Carrión, p.22). Lo anterior nos hace preguntarnos forzosamente, ¿quién realmente tiene derecho a la ciudad?

Aunado a lo antes dicho, a través de la movilidad y el transporte se pueden observar las relaciones de poder que aquejan a la Ciudad de México (Rojas, 2004). Es decir, jerarquizaciones sobre el lugar en el que las personas se ubican a sí mismos y son ubicados por otros. Cabe señalar, que esta desigualdad toma forma en la cotidianidad y en la representación del hábitat del cual son parte las personas. La situación clave para entender los problemas de movilidad tiene que ver con el espacio y la desigualdad física y social a la que se ven expuestos los sujetos. 
Es en este sentido que reconocer el espacio no sólo físico sino también social, nos ayuda a ubicar nuestro lugar, a mantenerlo, a jerarquizarlo y a ejercer poder desde nuestro espacio. Pierre Bourdieu (1999) identifica:

La capacidad de dominar el espacio, en especial adueñándose (material o simbólicamente) de los bienes escasos (públicos o privados) que se distribuyen en él, depende del capital poseído. Éste permite mantener a distancia a personas y cosas indeseables, al mismo tiempo que acercarse a las deseables (debido, entre otras cosas, a su riqueza en capital), y minimiza de ese modo el gasto (en particular de tiempo) necesario para apropiarse de ellas: la proximidad en el espacio físico permite que la proximidad en el espacio social produzca todos los efectos facilitando o favoreciendo la acumulación de capital social y, más precisamente, posibilitando el aprovechamiento constante de los encuentros a la vez fortuitos y previsibles que asegura la frecuentación de los lugares bien frecuentados [...] (p. 122)

Pese a lo anterior, la proximidad física en la movilidad revierte la lógica antes descrita: los encuentros entre los habitantes, la urbe y el transporte no son fortuitos ni previsibles; predomina el caos, el desorden y la violencia. Basta con recordar el metro a las horas pico y la cantidad de gente que se acomoda para que suban más y bajen menos de los vagones; o el tráfico a esas mismas horas en las que el sol, la lluvia o simplemente la cantidad de coches que circulan al día no le permiten al automovilista o al chofer encontrar una ruta alterna o avanzar más de 5 metros si se encuentran en un congestionamiento.

Sujetos en tránsito habitan la ciudad a partir de reglamentar el desorden para darle coherencia a ésta (Duhau y Giglia, 2008). De este modo, impera el imaginario de lo que la urbe debe ser. La podemos comparar con un ser mítico: un héroe o un villano, la vivencia de metrópoli nos permite pasar de un estado al otro en pocos minutos.

Las travesías urbanas son también viajes por las relaciones entre el orden y el desorden, donde se activa la memoria de las imágenes perdidas de la ciudad que fue, y se imagina cómo será, por ejemplo en el 2020, la hipermetrópolis que se insinúa a nuestro alrededor. Se accede a través de los viajes a un imaginario sobre 
la ciudad posible, se construye hipótesis - o se selecciona entre las disponiblespara explicar el sentido de los dramas urbanos. (Canclini et al., 2013, p. 46)

Ahora bien, la movilidad y la desigualdad urbana también ponen de manifiesto los espacio con mayor contradicción espacial. Ya con anterioridad mencionamos que uno de estos lugares, de los muchos que existen y cada vez proliferan más en la Ciudad de México, es Santa Fe.

\section{IV. ¿Cómo se llega a Santa Fe?}

\begin{abstract}
"Santa Fe cuenta ya con sus propias leyendas urbanas. Una de las más recurrentes es que fue planificada sin banquetas para abolir el espacio elemental que define a lo público: el ciudadano de a pie. No es así. Siempre existieron ahí banquetas, sólo que invariablemente estaban deshabitadas. El paisaje material que la constituye $y$ que se atraviesa siempre a velocidad (automóviles, camiones de lujo, gente a pie de prisa) encierra siempre un sentimiento de irreal, porque nadie lo habita; nada vive en él y nada podría vivir en su soledad."
\end{abstract}

llán Semo

Santa Fe es un distrito de lado poniente de la ciudad, tanto comercial como residencial, que forma parte de las delegaciones Cuajimalpa y Álvaro Obregón, el cual, se ha transformado de un lugar que albergaba tiraderos de basura (hasta 1980 que comenzaron los planes para un nuevo desarrollo urbano) a un espacio donde se han construido las principales oficinas de corporativos nacionales y trasnacionales.

Una de las principales características de Santa Fe que lo competen como un espacio insular es la forma en la que se construyó como megaproyecto. En 
éste se reedificó la infraestructura en cuanto a nuevos y lujosos edificios pero no en su acceso, sin bien eso lo mantenía como diferente y exclusivo; con el paso de tiempo y la mayor cantidad de personas que trabajan en él, llegar a Santa Fe se vuelve problemático:

Santa Fe no está articulado a la trama urbana pre-existente y se encuentra situado en las afueras de la ciudad. Estas características ayudaron a que el megaproyecto fuera parte de la ciudad pero a la vez se mantuviera como un lugar separado, nuevo y diferente. La condición urbana de Santa Fe también implicó que se requiriera una gran inversión en infraestructura, por lo que la venta de terrenos a los desarrolladores debía generar los recursos dirigidos a ella. Pero si bien se obtuvieron ganancias millonarias por la venta de terrenos expropiados, en los hechos parte del dinero fue usada para construir o renovar edificios públicos, y una cantidad significativa de estos recursos aparentemente "desapareció". (Moreno, 2008, p. 79)

Además, otra característica de este lugar como insular se observa al interior de sus circuitos arquitectónicos en el que pocas veces se entra de manera fácil. En Santa Fe se promueve alejarse y distinguirse de los "otros", muchas veces de los contiguos como los habitantes del pueblo de Santa Fe que cuentan con otra lógica distinta a los que habitan el megaproyecto, pero que forzosamente se ven en la necesidad de trabajar ahí:

[...] la continua secuencia de los distintos complejos arquitectónicos que se erigen en Santa Fe promueven, tanto de forma integral como de forma individual, la convivencia entre comunidades homogéneas que a través de su encierro buscan separarse del "otro", por ser culturalmente diferente cuando ingresa al interior de los conjuntos, es tratado con desconfianza, porque su diferencia cultural basada en su diferencia de clase se convierte en un poderoso argumento para hacerlo pasar como sospechoso. (Pérez, 2010, p. 25)

Esta desigualdad opera tanto para los que habitan las zonas más populares como para los que día con día se desplazan de lugares muy lejanos para ir a trabajar a este centro empresarial. La contradicción de la ciudad, del espacio 
público y de la movilidad -que no sólo aplica para Santa Fe- es que se piensa en un imaginario en el que los sujetos tienen el mismo derecho a habitar la ciudad y que los espacios públicos son para todos sin importar raza, clase o condición. El citadino pareciera puede disfrutar del espacio junto con otros citadinos en plena armonía y conformidad. (Duhau y Giglia, 2012)

No obstante, esto sólo es un tipo ideal, a lo que se enfrentan los trabajadores de Santa Fe dista mucho de lo anterior. Desde el inicio del día laboral, estos sujetos afrontan la mala calidad del transporte y una travesía que muchas veces implica más de dos horas para llegar a su destino con distintos modos de transporte. A lo anterior se suman las condiciones precarias, no sólo en el traslado sino también en el espacio laboral en el que se emplean. Los espacios públicos de Santa Fe no son tan públicos como pareciesen: sin cruces peatonales ni aceras amplias construidas para el peatón, ni lugares realmente públicos o donde puedan adquirir alimentos de manera económica y relajada, entre otras ausencias más.

Lo anterior, nuevamente cuestiona la disputa por el espacio público que atañe a los sujetos que transitan y laboran en Santa Fe; y que ya de por sí, la estructura citadina de movilidad los obliga a perder horas de su día para trasladarse de la casa al trabajo, todavía los constriñe a buscar lugares medianamente accesibles- para comer y esparcirse unos minutos y no encapsularse en los circuitos arquitectónicos. Las prácticas de lo formal y lo informal para habitar Santa Fe se vuelven formas de disputa y apropiación:

Las calles de Santa Fe rara vez son usadas por los peatones, excepto alrededor de la hora de la comida cuando los trabajadores salen de las oficinas y caminan hacia los coches que, estacionados con las cajuelas abiertas, venden gran variedad de alimentos. Todos estos comerciantes estacionan sus autos en lugares prohibidos, ya que las únicas áreas de estacionamiento permitidas se encuentran dentro de los edificios. Los empleados comen de pie en la calle o regresan a sus lugares de trabajo con su comida para consumirla en los comedores. Ésta es la nueva modalidad de puestos de comida callejera: usar coches, que son menos 
dañinos a la imagen de este espacio global supuestamente prístino y bien organizado, y utilizar teléfonos celulares para informar a los clientes sobre el menú del día y tomar pedidos. Los valores de la globalización neoliberal incluyen la flexibilidad y la adaptación a las demandas del mercado. El sector informal adopta estos valores y transforma sus estrategias para poder operar con éxito dentro del actual contexto social y urbano. (Moreno, 2008, p.81)

La cita antes señalada demuestra la falta de espacios a los que las personas que laboran en estos megaproyectos deberían tener derecho como parte de su construcción social. Asimismo, la primacía que existe sobre pensar el espacio público como lugares públicos, ejemplo de esto los centros comerciales, nuevamente pone de manifiesto la desigualdad y la falta realmente de espacios donde el consumo no sea lo primordial. Si bien existen formas de apropiación en estos lugares, en términos de desigualdad económica y social, los que tienen más son los que pueden comprar y no sentirse fuera de lugar.

Algunos se benefician más que otros con este desarrollo, sin embargo lo más significativo es que diferentes personas se apropian del espacio de diversas maneras. El centro comercial satisface la búsqueda de modernidad mediante nuevos componentes de identidad en los patrones de consumo. Este sitio produce de manera simultánea una nueva arena de negociación y de conflicto, creando desconocidas formas de exclusión sobre todo para los pobres. Aunque por el momento en Santa Fe y en áreas similares los centros comerciales parecen ser más públicos y democráticos que las calles, el potencial de segregación está implícito en su carácter privado (lbídem, p.83).

Cuando uno observa superficialmente a Santa Fe encuentra una ciudad global, un enclave de primer mundo en la Ciudad de México (Moreno, 2015), si uno se detiene y repara en los detalles descubre que las condiciones preexistentes del lugar no le permitieron materializar este objetivo; incluso el megaproyecto polarizó social y económicamente a los que habitan este espacio, ya sea de forma permanente o unas cuantas horas mientras laboran. 
Las nuevas Geografías de la Ciudad de México agudizan la desigualdad y el contraste social, una de éstas topografías es el caso de Santa Fe. Por un lado, existe un grupo de trabajadores de elites profesionales que se desplazan día a día a esta demarcación, que si bien no revierten la lógica de la mala planeación para llegar, cuentan con ingresos medianamente altos y laboran en los corporativos nacionales y trasnacionales que sostienen buena parte de la economía mexicana neoliberal.

Por el otro lado, se encuentran los trabajadores de servicios -ya sea de administración, limpieza o construcción - que mayoritariamente no cuentan con un sueldo bien remunerado ni con seguridad social, además de trasladarse y enfrentarse a un deficiente transporte y un mal plan de movilidad, o en otras palabras, precariedad laboral.

Esto necesariamente impacta en la vida cotidiana de las persona, la disputa por el espacio público y por una movilidad no tan deficiente se vuelven un cotidiano de la prácticas urbanas en dicho recinto. El megaproyecto de Santa Fe que se pensó sólo para que las personas accedieran a él en coche- es el ejemplo de la privatización y segregación del espacio público.

No obstante, los miles de trabajadores y colonos que lo habitan diariamente recrean tácticas e interiorizan el desorden de la ciudad y del megaproyecto para seguir laborando, regresar a sus casas, participar en el trabajo doméstico, convivir con sus familias y retornar a Santa Fe al día siguiente. ¿Cómo el espacio y la movilidad impacta en sus vidas?, ¿cómo los domestican?, ¿cómo lo habitan?, ¿cómo lo transforman? 


\section{CONCLUSIONES}

"[...] estamos en la ciudad, no podemos salir de ella sin caer en otra, idéntica aunque sea distinta, hablo de la ciudad inmensa, realidad diaria hecha de dos palabras: los otros, y en cada uno de ellos hay un yo cercenado de un nosotros, un yo a la deriva $[\ldots]$ "..

Octavio Paz

Pareciera que la movilidad se ha convertido en uno de los principales problemas que tanto el gobierno federal como el local han intentado resolver. $\mathrm{Si}$ bien se han implementado programas para combatir dichas dificultades, aún prevalecen condiciones de exclusión y marginalización que devienen en un bajo desarrollo social y económico para el país.

Las deficiencias en los tiempos de traslado, el costo y la calidad del transporte, así como el aumento del índice de contaminación han provocado que los habitantes de la Ciudad de México sufran los males que aquejan a una urbe con un inacabado plan de movilidad para largas y cortas distancias. Esta situación revela cuestionamientos imposibles de ignorar para una mejor calidad de vida integral e igualitaria; nuevamente se reitera el derecho de todos sus habitantes a la ciudad, sin importar clase social e ingresos económicos.

Además, la construcción de la urbanidad insular o espacios globales como Santa Fe se encuentran en la cúspide debido a la era del Neoliberalismo. Estos han acentuado el deterioro de las condiciones de vida de la mayoría de los habitantes de la Ciudad de México. La desigualdad de los salarios y el impacto de las polarización de los distintos grupos sociales con contrastante poder adquisitivo ha provocado que las clases más bajas sean las que sufran con mayor fuerza, la problemática de movilidad y estratificación espacial. 
El imaginario de Santa $\mathrm{Fe}$ ha impuesto una visión de lujo donde "forzosamente" está incluido el vehículo (y si es privado mejor). No existen fondas económicas para comer a lo que las empresas han solventado con comedores para sus trabajadores así como con camiones que salen de puntos específicos para dicho recinto. Aunque estas últimas medidas resuelven medianamente estas encrucijadas es necesario puntualizar que una vez implementadas se olvidan de los espacios públicos a los que el trabajador debería tener derecho como parte de su construcción social. Comer en el mismo lugar de trabajo y tener que llegar a puntos específicos que no siempre son cercanos al lugar de vivienda son medidas paliativas que no resuelven ni resolverán el problema en sí.

En la actualidad, la movilidad en Santa Fe se encuentra en cuestión crítica, no sólo por la falta de alternativas para desplazarse, sino también por la construcción del tren Interurbano que iría de Observatorio hasta Toluca y que en un principio recorrería la Av. Vasco de Quiroga, arteria principal de Santa Fe. El diseño de dicha obra se vio obligado a cambiar hacia la Barranca del Río Tacubaya debido a los múltiples cuestionamientos suscitados, en especial sobre la saturación vehicular que traería consigo, otorgando nuevamente preferencia al uso del automóvil por encima de cualquier otro medio de transporte como el público. ¿Qué papel juegan los trabajadores con ingresos bajos que diariamente se desplazan a esta zona?, ¿cómo les repercute la construcción de un nuevo transporte?, ¿el tren Interurbano está pensado para ellos?

Actualmente, la mayoría de los habitantes que viven en la ciudad o en las zonas conurbadas de la Ciudad de México pasan más de dos horas en el traslado diario -de sus trabajos a sus recintos laborales- y dos horas más para su regreso. Lo anterior nos hace pensar que al ocuparse tanto tiempo en el transporte entonces también se vive y por lo tanto se habita ahí. ¿Cómo ocupan el tiempo mientras se trasladan? Es común que en el transporte público observemos a gente leyendo, comiendo, arreglándose o incluso durmiendo. En el caso de los automovilistas algunos van teniendo juntas por el teléfono celular o realizan alguna actividad productiva durante el trayecto. Éstas son formas de habitar como se 
habita en casa, porque estos espacios y estas geografías se domestican, no son lugares de paso o no lugares.

Con lo anterior llegamos a la conclusión de que la movilidad parte de cuatro componentes indisolubles: la ciudad, los lugares, los modos de transporte en los que se viaja y el cuerpo de los sujetos. Estos elementos nos permiten construir multiescalarmente la investigación; ya sea desde la primera escala micro que es el cuerpo -donde la desigualdad en la movilidad marca y deja huellas corpóreas- 0 desde lo macro que sería la ciudad y el peso que tiene la planeación urbana.

Por último, cabe señalar que pensar la ciudad es cuestionarnos desde un plano empírico si es realmente posible el derecho a la ciudad como acceso igualitario al espacio público. Y a su vez, contraponerlo con la planificación y las políticas urbanas realizadas tanto por el gobierno como por los arquitectos y urbanistas. ¿Cómo se confronta el imaginario sobre el derecho a disfrutar la ciudad con las prácticas citadinas y el impacto de la infraestructura? Son múltiples las preguntas que surgen de este fenómeno y que por el momento no pueden ser planteados sino a través de una investigación empírica. 


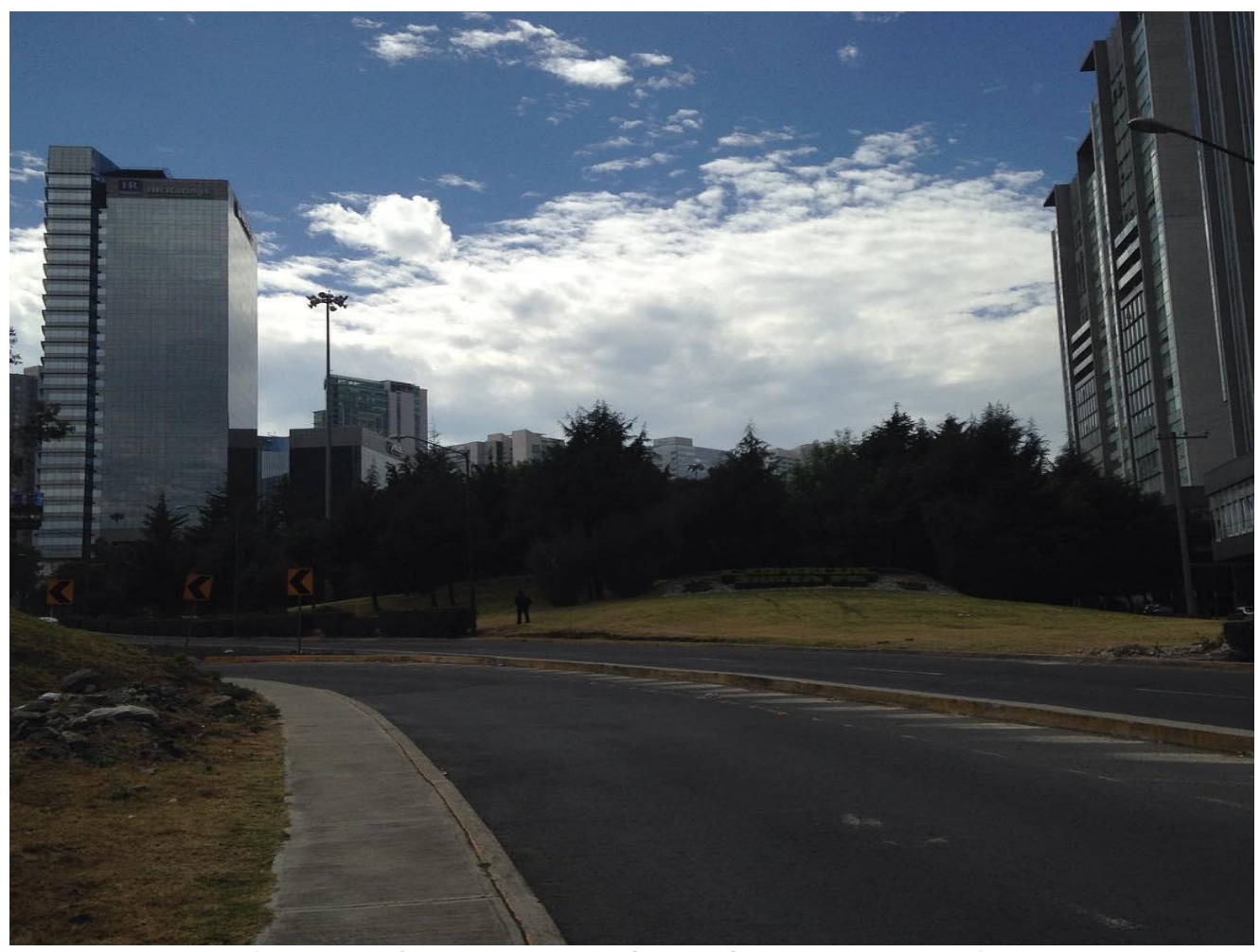

(Fotografía de Tanisha Silva, Santa Fe, 2015.)

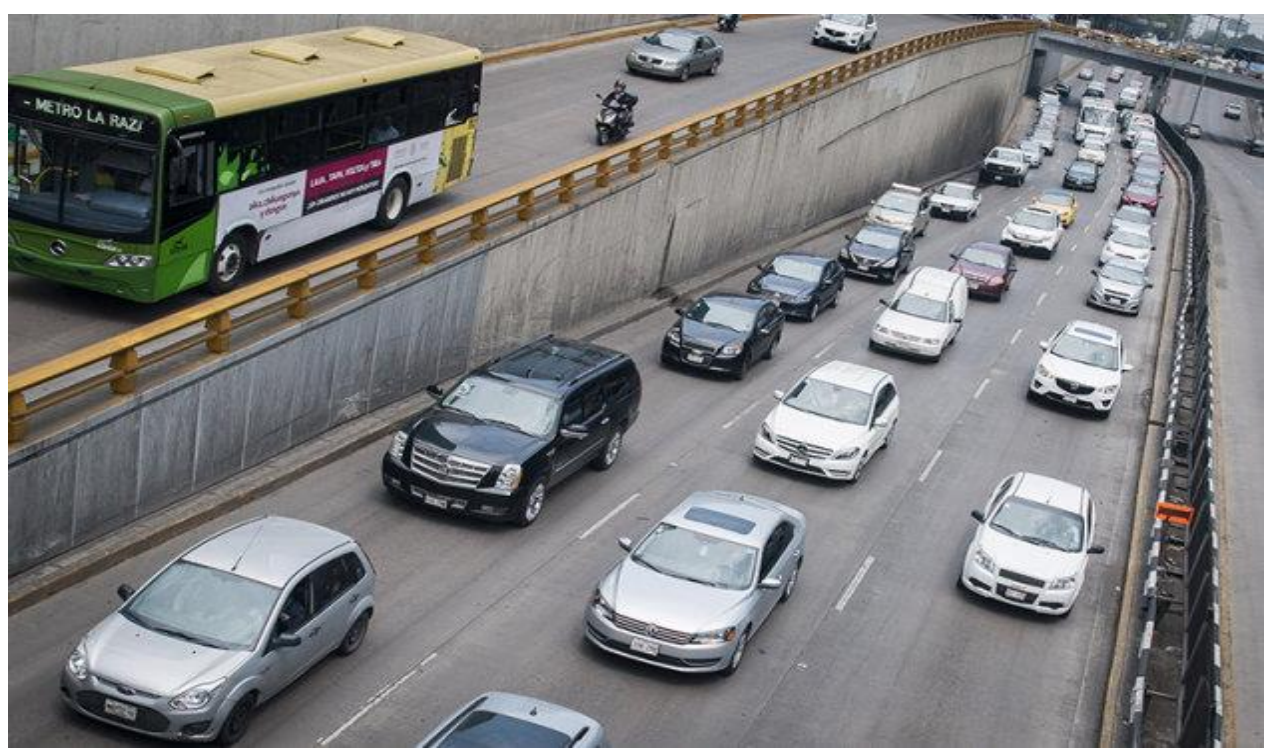

(Fotografía tomada por Diego Simón Sánchez, Circuito Interior) 


\section{REFERENCIAS}

- Agencia de Gestión Urbana de la Ciudad de México (2015). Síntesis informativa, [en línea] http://www.agu.df.gob.mx/sintesis/index.php/cambios-aruta-del-tren-interurbano-beneficiaran-a-capitalinos/

- Álvarez, Andrés (2010). "El metro, un espacio de interacciones. El caso de los homosexuales", tesis de licenciatura, UNAM-FCPyS, México.

- Apaolaza, Ascencio Ricardo (2013). "Los debates sobre transporte urbano, movilidad cotidiana y exclusión social. Una revisión desde el caso Argentino." Acta Científica XXIX Congreso de la Asociación Latinoamericana de Sociología [en línea], recuperado de http://actacientifica.servicioit.cl/biblioteca/gt/GT8/GT8_AsencioA.pdf- ISBN: 978956-19-0828-

- Auge, Marc (2000). Los No Lugares. Espacios del anonimato. Una antropología de la sobremodernidad, Barcelona, España: Gedisa.

- Bolañios, Sánchez Ángel (2015). "Limitar el trazo de línea 7 del Metrobús provocará caos vial: asambleísta". La Jornada [en línea] 2015. http://www.jornada.unam.mx/ultimas/2015/06/30/limitar-el-trazo-de-linea-7-delmetrobus-provocara-caos-vial-asambleista-2962.html

- Capron, Guénola y Ruth Pérez (2016). "La experiencia cotidiana del automóvil y del transporte público en la Zona Metropolitana del Valle de México". En Alteridades, año 26, núm 52, julio-diciembre, pp. 11-21.

- Carrión, Fernanda (2012). "El espacio público es una relación, no un espacio" en Ramírez, Kuri Patricia (coord.). La reinvención del espacio público en la ciudad fragmentada, UNAM/IIS/Posgrado de Maestría y Doctorado en Urbanismo, México.

- Cuarto Informe de Gobierno de la Ciudad de México )

- Duhau, Emilio y Angela Giglia (2008). Las reglas del desorden: habitar la metrópoli, México: Siglo XXI/Universidad Autónoma Metropolitana.

- Duhau, Emilio y Angela Giglia (2012). "El Espacio Público en la Ciudad de México. De las Teorías a las Prácticas" en Los grandes problemas de México. Manuel Ordorica y Jean-François Prud'homme (coord.). [en línea] México: Colmex. http://www.colmex.mx/gpm/images/PDF/l POBLACION.pdf

- Duhau, Emilio y Angela Giglia (2016). Metrópoli , espacio público y consumo, México: FCE.

- García Canclini, Néstor, Alejandro Castellanos y Ana Rosas Mantecón (2013). La Ciudad de los Viajeros. Travesías e Imaginarios Urbanos. México 19402000, México: FCE/UAM. 
- García Canclini, Nestor (2004). Diferentes, Desiguales y Desconectados. Mapas de la interculturalidad, Barcelona, España: Gedisa Editorial.

- Giglia, Angela (2012). El habitar y la cultura. Perspectivas teóricas y de investigación, México; Anthropos/UAM-Iztapalapa.

- Giglia, Angela (2013), Entre el bien común y la ciudad insular: la renovación urbana en la Ciudad de México en Alteridades, vol. 23, núm. 46, juliodiciembre, pp. 27-38, México: UAM-Izt

- Gobierno de la Ciudad de México, Cuarto Informe de Gobierno de la Ciudad de México

http://www.cdmx.gob.mx/storage/app/uploads/public/57d/c84/8ce/57dc848ceb3 d0920333296.pdf

- Gutiérrez, Andrea (2010). "Movilidad, transporte y acceso: una renovación aplicada al ordenamiento territorial". Scripta Nova. Revista Electrónica de Geografía y Ciencias Sociales [en línea]. Barcelona, España: Universidad de Barcelona, vol. XIV, no 331 (86). <http://www.ub.es/geocrit/sn/sn-331/sn-33186.htm>. [ISSN: 1138-9788].

- Le Breton, David (2017). Elogio al Caminar, México: Ediciones Siruela.

- Lindón, Alicia (2006). Territorialidad y Género, en: Pensar y habitar la ciudad: afectividad, memoria y significado / coord. por Patricia Ramírez Kuri, Miguel Angel Aguilar Díaz, ISBN 84-7658-764-3, págs. 13-32

- Moreno, María (2015). Geografías en Construcción. El Megaproyecto de Santa Fe en la Ciudad de México, México: UAM-Cuajimalpa

- Moreno, María (2008). "La producción espacial de lo global: lo público y lo privado en Santa Fe, Ciudad de México" en Alteridades, vol. 18, núm. 36, juliodiciembre, . http://www.redalyc.org/pdf/747/74716004007.pdf

- ONU-Hábitat. Reporte Nacional de Movilidad Urbana en México 2014-2015. http://www.onuhabitat.org/Reporte\%20Nacional\%20de\%20Movilidad\%20Urban a\%20en\%20Mexico\%202014-2015\%20-\%20Final.pdf

- Paz, Octavio. (1998). Hablo de la ciudad. El fuego de cada día, Barcelona: Ed. Seix Barral.

- Pérez, Margarita (2010). Santa Fe: ciudad, espacio y globalización. México: Universidad lberoamericana.

- Pujadas, Joan (2012). "Itinerarios metropolitanos: policentrismo, movilidad y trayectorias personales en la ciudad porosa" en Revista bibliográfica de Geografía y Ciencias Sociales Vol. XVII, ํo 968, Universidad de Barcelona. 
- Ramírez, Kuri Patricia (coord.) (2003). Espacio Público y Reconstrucción de Ciudadanía, México: Facultad Latinoamericana de Ciencias Sociales/ Miguel Ángel Porrúa.

- Roa, Herty, Carolina Rojas, Juan Antonio Carrasco, Alejandro Tudela. "Movilidad urbana e indicadores de exclusión social del sistema de transporte: evidencia en una ciudad intermedia chilena." Revista Transporte y Territorio [en línea] 2013, ( ) <http://www.redalyc.org/articulo.oa?id=333027381004> ISSN

- Rojas Alberto. (2004) "Espacio y Tiempo en la Sociedades Globales según Manuel Castells" en Praxis, No.57.

- Sañudo, Andrés ¿Qué queremos: una gran ciudad o un gran estacionamiento? En The Huffingtonpost http://www.huffingtonpost.com.mx/andres-sanudo/que-queremos-una-granciudad-o-un-gran-estacionamiento/

- Semo, llán (2016). "Santa Fe: pasajes a la oquedad" en La Jornada, año 32, no. 11286, México, http://www.jornada.unam.mx/2016/01/02/opinion/012a2pol

- Shoshan, Nitzan (2015). "Las temporalidades de la crisis en Santa Fe, Distrito Federal”. Sociológica, año 30, número 84, [en línea] enero-abril http://www.revistasociologica.com.mx/secciones.asp?seccion=Art\%EDculo

- Signorelli, Amalia (1999). Antropología Urbana. México: Antrophos/UAM-Izt.

- Simón, Diego (S/A). Cuarto Oscuro. http://cuartoscuro.com.mx

- Sistema Nacional de Clasificación de Ocupaciones (SINCO) 2011 http://www3.inegi.org.mx/sistemas/clasificaciones/sinco/sinco.aspx

- Sosa, Iván (2015). "Desprecia inmuebles derrumbe de Santa Fe" en Reforma, http://www.reforma.com/aplicaciones/articulo/default.aspx?id=682535

- Villoro, Juan (2005). "Bienvenidos a la cultura del postapocalipisis! "La ciudad de México: mujer barbuda" http://hellodf.com/villoro/ 


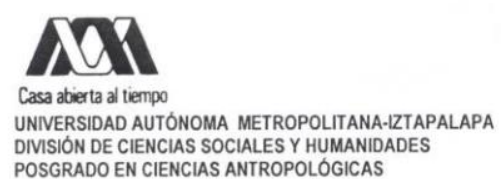

POSGRADO EN CIENCIAS ANTROPOLOGICAS

CONSTANCIA DE EVALUACIÓN DEL ENSAYO

PARA LA OBTENCIÓN DEL DIPLOMA EN LA

ESPECIALIZACIÓN EN ANTROPOLOGÍA DE LA CULTURA

\begin{tabular}{|l|l|c|}
\hline DUA & MES & ANo \\
19 & 07 & 2017 \\
\hline
\end{tabular}

ALUMNA: SILVA AGUILAR SANDRA TANISHA

MATRICULA: 2163801378

TRIMFSTRE $17-\mathrm{P}$

DIRECTOR: NÉSTOR RAÚL GARCÍA CANCLINI

LA ALUMNA PRESENTÓ EL ENSAYO TITULADO:

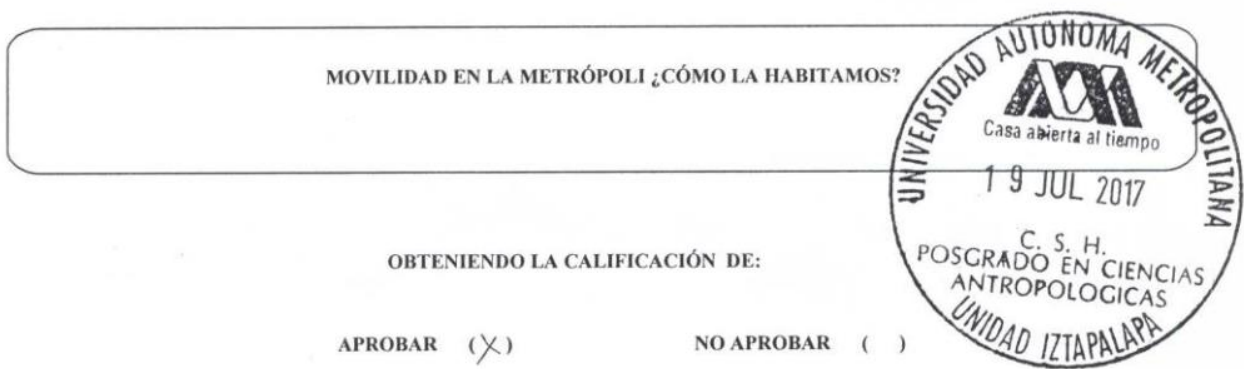

DIRECTOR DEL ENSAYO

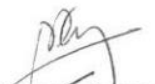

DR. NÉSTOR RAUUL GARCÍA CANCLINI

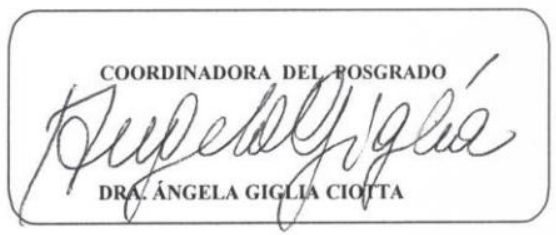

